\title{
EL TRABAJO PENITENCIARIO EN COLOMBIA. DESARROLLO JURISPRUDENCIAL DE LA CORTE CONSTITUCIONAL SOBRE EL DERECHO AL TRABAJO PENITENCIARIO DESDE 1992 HASTA EL $2020^{1}$
}

Brenda Julieth Archila Dávila

\author{
PRISON LABOR IN COLOMBIA. JURISPRUDENTIAL \\ DEVELOPMENT BY THE CONSTITUTIONAL COURT ON \\ THE RIGHT TO PRISON LABOR FROM 1992 TO 2020 \\ O TRABALHO PENITENCIÁRIO NA COLÔMBIA. DESENVOLVIMENTO \\ JURISPRUDENCIAL DA CORTE CONSTITUCIONAL SOBRE O DIREITO \\ AO TRABALHO NO ÂMBITO PENITENCIÁRIO DE 1992 A 2020 \\ Fecha de recepción: $1 .^{\circ}$ de junio del 2021 \\ Fecha de aceptación: 9 de julio del 2021 \\ Disponible en línea: 9 de agosto del 2021
}

Sugerencia de citación: Archila Dávila, B. J. (2021). El trabajo penitenciario en Colombia.Desarrollo jurisprudencial de la Corte Constitucional sobre el derecho al trabajo penitenciario desde 1992 hasta el 2020. Razón Crítica, (11), 97-126. https://doi.org/10.21789/25007807.1789

(1) Artículo de investigación, desarrollado en el marco del proyecto "Formación jurídica a partir de la metodología de caso" de la Universidad de Bogotá Jorge Tadeo Lozano.

(2) Candidata a magíster de la Universidad Externado de Colombia, Maestría en Justicia y Tutela Efectiva de los Derechos con Énfasis en Derecho Procesal | Abogada de la Universidad de Bogotá Jorge Tadeo Lozano, Colombia | Miembro fundador de la Clínica Jurídica sobre Derechos Humanos y Derecho Constitucional de la misma universidad. Miembro nominativo e investigadora del Instituto Internacional de Derechos Humanos, Capítulo Colombia dayuarcajps@gmail.com | https://orcid.org/0000-0001-5539-7349 


\section{R E S U M E N}

El derecho al trabajo es un derecho fundamental y un derecho humano. El Estado debe garantizar su materialización frente a todas las personas, bajo el principio de dignidad humana. La presente investigación abordó el avance jurisprudencial de la Corte Constitucional respecto al derecho al trabajo penitenciario en Colombia entre 1992 y el 2020. Para el desarrollo de la investigación se realizó una línea jurisprudencial utilizando el método censitario, que permitió realizar un estudio cualitativo y cuantitativo que respondió a los caracteres de sistematicidad, descripción y conexión sobre la tesis adoptada por la Corte Constitucional en lo que respecta al derecho al trabajo en los centros penitenciarios. Obteniendo como resultado que las personas privadas de la libertad tienen los mismos derechos laborales que cualquier otro trabajador, el Estado tiene a su cargo el desarrollo de diversas estrategias para la resocialización de los reos, enfatizando que el trabajo penitenciario en condiciones apropiadas es una proyección de la justicia restaurativa.

PALABRAS CLAVE: trabajo penitenciario; reinserción; pena; derechos humanos. 


\section{A B S T R A C T}

The right to work makes part of fundamental and human rights. Therefore, the State must guarantee its materialization for all people under the principle of human dignity. This study addressed the jurisprudential advance by the Constitutional Court regarding the right to prison labor in Colombia between 1992 and 2020. For the development of the research, a jurisprudential line was carried out using the census method, which allowed a qualitative and quantitative study that responded to the characteristics of systematicity, description and connection presented in the thesis adopted by the Colombian Constitutional Court regarding prison labor. As a result, it was determined that inmates have the same labor rights as any other worker and that the State is in charge of developing various strategies for their re-socialization, emphasizing that prison labor under appropriate conditions is a projection of restorative justice.

Keywords: Prison labor; reinsertion; sentence;

Human Rights.

\section{R E S U M O}

O direito ao trabalho é um direito fundamental e um direito humano. O Estado deve garantir sua materialização a todas as pessoas, sob o princípio de dignidade humana. Nesta pesquisa, foi abordado o progresso jurisprudencial da Corte Constitucional a respeito do direito ao trabalho no âmbito penitenciário na Colômbia entre 1992 e 2020. Para o desenvolvimento da pesquisa, foi realizada uma linha jurisprudencial que utilizou o método censitário, o qual permitiu realizar um estudo qualitativo e quantitativo que respondeu aos caracteres de sistematicidade, descrição e conexão sobre a tese adotada pela Corte Constitucional no que se refere ao direito ao trabalho em centros penitenciários. Como resultado, obteve-se que as pessoas privadas de liberdade têm os mesmos direitos trabalhistas que qualquer outro trabalhador. Nesse sentido, o Estado tem a responsabilidade de desenvolver estratégias para ressocializar os réus, tendo em vista que o trabalho penitenciário em condições apropriadas é uma projeção da justiça restaurativa.

PALAVRAS-CHAVE: trabalho penitenciário; reinserção; pena; direitos humanos. 
Los derechos humanos son parte integral de una buena gestión penitenciaria, dado que esta se debe desarrollar dentro de un marco ético-jurídico para satisfacer los fines propios de la pena y evitar abusos de poder que pongan en riesgo los derechos de los reclusos. Así las cosas, puede decirse que una de las pruebas más grandes de este respeto por la humanidad reside en el modo en que la sociedad trata a quienes han infringido o han sido acusados de infringir la legislación penal. Por esto, en los centros carcelarios y penitenciarios deben existir programas integrales de actividades constructivas que ayuden a los reclusos a mejorar su situación. Como mínimo, la experiencia de la prisión no debe dejar a los reclusos en una situación peor a la que se encontraban al inicio de su condena; por el contrario, debe ayudarles a mantener y mejorar su salud, su funcionamiento intelectual y social (Coyle, 2009). Para ello, pueden ser empleados diferentes mecanismos como, por ejemplo, la educación, el deporte, la recreación y el trabajo. Este último, “[...] facilita la resocialización del recluso, a través del aprendizaje e interiorización de pautas de comportamiento, valores y hábitos (de autodisciplina, puntualidad, responsabilidad, valoración del esfuerzo y convivencia)" (Moner \& Artiles, 2008, p. 228). Así, el trabajo penitenciario ayudaría a cumplir con la función de facilitar la posterior reinserción social y laboral del recluso.

El presente trabajo pretende explorar el desarrollo del derecho al trabajo de las personas privadas de su libertad en Colombia. Esto se hace mediante el análisis de los fallos proferidos por el máximo tribunal constitucional colombiano. Para dicho análisis se desarrollará inicialmente la presentación del problema y pregunta de investigación para después, ejecutar la descripción de la metodología empleada y previo a las conclusiones, exponer los resultados obtenidos al clasificar y calificar cada uno de estos fallos. 


\section{PLANTEAMIENTO DEL PROBLEMA DE INVESTIGACIÓN}

La Corte Constitucional colombiana (en adelante, Corte o Tribunal) ha definido el concepto de política criminal como "[...] el conjunto de respuestas que un Estado estima necesario adoptar para hacerle frente a conductas consideradas reprochables o causantes de perjuicio social con el fin de garantizar la protección de los intereses esenciales del Estado y de los derechos de los residentes en el territorio bajo su jurisdicción” (Corte Constitucional, Sentencia C 936, 2010). Analizado el planteamiento anterior, se concluye que la política criminal en el Estado colombiano se orienta, en primera medida, a atender de manera reactiva las conductas criminales sobre las cuales la sociedad exige regulación, debido a la realidad social del país y las problemáticas que lo acogen. Como segunda medida, busca investigar, juzgar y condenar a los autores de estas acciones.

No obstante, la política criminal no puede encaminarse simplemente a la materialización de la justicia retributiva, sino que debe acoplarse a los fines de la justicia restaurativa ${ }^{3}$, la cual como ha establecido la Corte (1996) también busca resocializar a los reos al culminar su pena (Corte Constitucional, Sentencia C 261, 1996) ${ }^{4}$. Ahí se debe entender que, existiendo un resultado positivo en la reinserción social y laboral del condenado a través del trabajo penitenciario, resultaría siendo este un componente preventivo en política criminal en lo que se refiere a la reincidencia en la comisión de delitos, tal como lo ha resaltado la Corte $\left(1996\right.$, Sentencia C 430) ${ }^{5}$.

3 La justicia restaurativa busca quebrantar la dimensión retributiva del derecho penal y otorgar prioridad no solo al daño causado y a los sujetos afectados, sino también a la reconciliación de aquellos.

Todo proceso en el que la víctima y el imputado, acusado o sentenciado participan conjuntamente de forma activa en la resolución de cuestiones derivadas del delito en busca de un resultado restaurativo, con o sin la participación de un facilitador. Entiende por resultado restaurativo el acuerdo encaminado a atender las necesidades y responsabilidades individuales y colectivas de las partes y a lograr la reintegración de la víctima y del infractor en la comunidad en busca de la reparación, la restitución y el servicio a la comunidad (Ley 906, 2004, art. 518).

\footnotetext{
4 En un Estado social de derecho, a partir de la noción de dignidad y de la autonomía de la persona que no se pierden por el hecho de estar purgando una condena, la reincorporación a la vida social se constituye en una garantía material del penado, ya que no se trata de la imposición estatal de un esquema de valores, sino en crear bases para que el individuo se desarrolle libremente y de algún modo, contrarrestar las consecuencias desocializadoras de la intervención penal.

5 La finalidad de la pena en nuestro sistema jurídico un fin preventivo, que se cumple
} 
Dada la importancia que ostenta el trabajo penitenciario y carcelario, el presente trabajo pretende abordar el desarrollo jurisprudencial que ha realizado la Corte frente a este componente. Entendiendo el mismo no solo como un elemento de la política criminal, sino un derecho propiamente dicho de las personas que se encuentran recluidos en estos centros. La Ley 1.709 del 2014 definió el trabajo penitenciario y carcelario como:

El trabajo es un derecho y una obligación social ${ }^{6}$ y goza en todas sus modalidades de la protección especial del Estado. Todas las personas privadas de la libertad tienen derecho al trabajo en condiciones dignas y justas. En los establecimientos de reclusión es un medio terapéutico adecuado a los fines de la resocialización. Los procesados tendrán derecho a trabajar y a desarrollar actividades productivas. No tendrá carácter aflictivo ni podrá ser aplicado como sanción disciplinaria. Se organizará atendiéndolas aptitudes y capacidades de los internos, permitiéndoles dentro de lo posible escoger entre las diferentes opciones existentes en el centro de reclusión (Ley 1.709, 2014).

La relevancia de la doctrina de la Corte para la comprensión de la normativa nacional y su integración con las normas del bloque de constitucionalidad (Fuentes-Contreras, 2010; 2017) llevó a la siguiente pregunta de investigación: ¿Cuál es el abordaje jurisprudencial de la Corte Constitucional colombiana en materia de garantías frente al derecho al trabajo en los centros penitenciarios y carcelarios desde 1992 hasta el 2020?7

En consecuencia, en la presente investigación se estudiaron diferentes pronunciamientos de la Corte, en los cuales existiera una mención acerca del derecho al trabajo de las personas recluidas en centros penitenciarios y carcelarios. A su vez, se enfoca en las providencias que son progresivas respecto el derecho al trabajo de las personas privadas de su libertad,

\footnotetext{
básicamente en el momento del establecimiento legislativo de la sanción, la cual se presenta como la amenaza de un mal ante la violación de las prohibiciones; un fin retributivo, que se manifiesta en el momento de la imposición judicial de la pena, y un fin resocializador que orienta la ejecución de la misma, de conformidad con los principios humanistas y las normas de derecho internacional adoptadas.

6 Los convenios 29 y 105 de la Organización Internacional del Trabajo (OIT) establecen como excepción las condenas por delitos políticos, a las mujeres embarazadas o parturientas, a las personas mayores de 60 años, el fundamento de la obligación de trabajar debe ser una sentencia judicial que declare al individuo culpable. De tal suerte, las personas que han sido detenidas sin haber sido juzgadas o las que esperan ser procesadas, no deben estar obligadas a hacer ningún trabajo, pero naturalmente pueden llevarlo a cabo siempre y cuando de manera voluntaria se ofrezcan a ello.

7 La presente investigación se abordó de manera general frente al trabajo penitenciario y carcelario de hombres, mujeres y personas no binarias en Colombia. La razón es que no se encontró bibliografía suficiente en la cual se hiciera distinción de las clasificaciones mencionadas previamente.
} 
ya sea porque establecen una nueva garantía al derecho, amplían una garantía ya establecida o eliminan una limitante del derecho.

\section{METODOLOGÍA}

En razón al carácter exploratorio del presente artículo, se recolectaron providencias judiciales de la Corte a través del método censitario, como ha sido denominado por el profesor Edgar Fuentes (2010). Se ha optado por dicho método, ya que este abarca de mejor manera la posible respuesta a la pregunta investigativa y permite realizar un estudio cualitativo que responda a los caracteres de sistematicidad, descripción y correlacional sobre la tesis adoptada por la Corte, entre 1992 y el 2020, en lo que respecta al derecho al trabajo en los centros penitenciarios. Así, teniendo como objeto de estudio principal la jurisprudencia de la Corte, en el lapso expuesto, se empleará el método para crear, en forma conceptual, una línea jurisprudencial del tema aquí seleccionado.

En este sentido, debe recordarse que el método censitario se entiende así:

En términos generales, el censo que, normalmente, se emplea para la recolección de datos demográficos, parte de la denominada enumeración individual:

La idea básica que hay tras un censo es la de enumerar separadamente a cada individuo con sus correspondientes características que también deben ser anotadas en forma separada. Lo importante es cubrir a todos los individuos como sujeto de enumeración, pero ello no impide que al usar la técnica del muestreo combinada con la del censo, algunas preguntas específicas solo se hagan a las personas incluidas en la muestra [...].

En consecuencia, y bajo la idea de cubrir a todos los individuos, para el caso concreto providencias de la Corte Constitucional, el método censitario, como propuesta investigativa en el ámbito de las líneas jurisprudenciales, procura efectuar una individualización de cada una de las fuentes primarias de investigación, mediante la enumeración y recolección de las providencias proferidas por la Corte Constitucional (Fuentes-Contreras, 2010, p. 130). 
Se descartaron otras técnicas investigativas, como la ingeniería de reversa (López, 2006; 2016a) y el recolectivo diseñado por Suárez López y FuentesContreras (2015, p. 65). Aunque estas metodologías contienen elementos útiles para dar respuesta al interrogante de investigación, se desecharon por no ser suficientes para el objetivo de esta investigación, ya que estos no realizan una clasificación de los pronunciamientos de la Corte, sino que, por el contrario, son compilados sin realizar distinción. Además, los métodos no suelen abarcar las menciones realizadas en los salvamentos o aclaraciones de voto, lo cual no permitiría realizar una investigación integral, pues, estos últimos permiten tener un desarrollo más extensivo del derecho y que, en algunos casos, a partir de estos, el Tribunal se pronuncia con posterioridad (Pulido, 2018; 2008). Las situaciones mencionadas anteriormente acarrean que la implementación de estas técnicas pueda ser consideradas como insuficientes. En consecuencia, se debía optar por el método censitario (Rivas-Ramírez y Fuentes-Contreras, 2021; Fuentes- Contreras y Rivas-Ramírez, 2020; Fuentes-Contreras, 2020; Fuentes-Contreras, 2019; Fuentes-Contreras, Suárez López y Rincón Villegas, 2014; Fuentes-Contreras y Cárdenas- Contreras, 2021).

De la misma forma, el método censitario se encuentra estructurado por dos subdivisiones: el lato sensu, o temático ${ }^{8}$, y stricto sensu, o literal ${ }^{9}$. En el artículo actual, se eligió el lato sensu, empleando como temática "trabajo carcelario" y "trabajo penitenciario". Estas temáticas se eligieron porque la Corte se ha pronunciado utilizando las dos expresiones.

Ahora bien, cuando se usa la temática "trabajo penitenciario" se obtuvieron 15 providencias ${ }^{10}$; cuando se buscó "trabajo carcelario", se llegó a 21 providencias. Después de realizar una revisión de las sentencias, se pudo notar que algunas de estas se repetían, quedando18 providencias finalmente, frente a las 36 iniciales. A continuación, se exponen por año los datos obtenidos (tabla 1).

\footnotetext{
8 Este se vincula con una búsqueda temática de un concepto jurídico de interés, es decir, se emplea una preselección de providencias que han sido clasificadas con anterioridad por la propia Corte Constitucional y se hace un rastreo e individualización de estas.

9 Este desarrolla la idea de identificar en cuántas oportunidades un término se utiliza en la totalidad de pronunciamientos que realiza la Corte Constitucional colombiana.

10 Sentencia T 1007/05 (se repite dos veces), sentencia C 394/95 (se repite tres veces), sentencia $\mathrm{T}$ 429(se repite dos veces), sentencia T 756/15(se repite cinco veces), sentencia C 151/00 (se repite cuatro veces), sentencia T 1.303/05(se repite tres veces), sentencia T 1326/05(se repite dos veces), sentencia T 865/12(se repite dos veces), sentencia $\mathrm{T} 756 / 15$ (se repite cuatro veces).
} 
Tabla 1. Pronunciamiento de la Corte Constitucional frente al uso de la expresión “trabajo penitenciario y trabajo carcelario" entre 1992 y el 2020

\begin{tabular}{|c|c|c|c|c|c|}
\hline \multirow[b]{2}{*}{ Año } & \multirow[b]{2}{*}{ Autos } & \multicolumn{3}{|c|}{ Sentencias } & \multirow[b]{2}{*}{ Total } \\
\hline & & C & SU & $\mathbf{T}$ & \\
\hline 1992 & 0 & 0 & 0 & 1 & 1 \\
\hline 1993 & 0 & 0 & 0 & 1 & 1 \\
\hline 1994 & 0 & 0 & 0 & 0 & 0 \\
\hline 1995 & 0 & 1 & 0 & 0 & 1 \\
\hline 1996 & 0 & 1 & 0 & 0 & 1 \\
\hline 1997 & 0 & 0 & 0 & 0 & 0 \\
\hline 1998 & 0 & 0 & 0 & 0 & 0 \\
\hline 1999 & 0 & 0 & 0 & 0 & 0 \\
\hline 2000 & 0 & 1 & 0 & 0 & 1 \\
\hline 2001 & 0 & 0 & 0 & 0 & 0 \\
\hline 2002 & 0 & 0 & 0 & 0 & 0 \\
\hline 2003 & 0 & 0 & 0 & 1 & 1 \\
\hline 2004 & 0 & 0 & 0 & 0 & 0 \\
\hline 2005 & 0 & 0 & 0 & 3 & 3 \\
\hline 2006 & 0 & 0 & 0 & 0 & 0 \\
\hline 2007 & 0 & 0 & 0 & 0 & 0 \\
\hline 2008 & 0 & 0 & 0 & 0 & 0 \\
\hline 2009 & 0 & 0 & 0 & 0 & 0 \\
\hline 2010 & 0 & 0 & 0 & 1 & 1 \\
\hline 2011 & 0 & 0 & 0 & 1 & 1 \\
\hline 2012 & 0 & 0 & 0 & 1 & 1 \\
\hline 2013 & 0 & 0 & 0 & 0 & 0 \\
\hline 2014 & 1 & 0 & 0 & 1 & 2 \\
\hline 2015 & 0 & 0 & 0 & 1 & 1 \\
\hline 2016 & 0 & 0 & 0 & 0 & 0 \\
\hline 2017 & 0 & 0 & 0 & 0 & 0 \\
\hline 2018 & 0 & 0 & 0 & 1 & 1 \\
\hline 2019 & 0 & 1 & 0 & 0 & 1 \\
\hline 2020 & 0 & 0 & 0 & 0 & 0 \\
\hline & & Total & & & 17 \\
\hline
\end{tabular}

Nota. Sentencias C: control de constitucionalidad. Sentencias SU: unificación de tutela. Sentencias T: revisión de tutela.

Fuente: elaboración propia. 


\section{RESULTADOS}

En desarrollo a la metodología de investigación, se realizó el fichaje de 18 providencias expedidas por la Corte en el lapso de 1992 al 2020, debido a que en la indagación en el buscador temático de la Corte resultaron 17; luego de su lectura, se encontró una nueva sentencia que no aparecía en la búsqueda inicial y, por su contenido y relevancia jurídica, se incluyó: esta sentencia es la T 009/93.

Para la presente investigación, se analizó cada fallo del Tribunal, con la intención de poder clasificar y otorgar un puntaje a cada pronunciamiento a partir del reconocimiento, creación, desarrollo, mención o eliminación de derechos a los reclusos en materia laboral (tabla 2):

Tabla 2. Valoración de las providencias de la Corte Constitucional sobre el trabajo penitenciario y carcelario (1992- 2020).

Formato de clasificación y puntuación de las providencias analizadas

\begin{tabular}{|c|c|}
\hline Clasificación & Puntaje \\
\hline Creación de una garantía & 4 \\
\hline Reconocimiento de una garantía & 3 \\
\hline Desarrollo de una garantía & 2 \\
\hline Reiteración o mención de una garantía & 1 \\
\hline Falta de pronunciamiento frente al derecho & 0 \\
\hline Eliminación de una garantía & -1 \\
\hline
\end{tabular}

Fuente: elaboración propia.

Es importante distinguir que las anteriores clasificaciones no son excluyentes, por tanto, podrán sumarse o restarse puntos en los casos en que concurran varias de estas, para lo cual se obtendrá un puntaje final, que será el que se presentará en las tablas.

Ahora bien, a partir del examen de las providencias, se determinó dar mayor relevancia a ciertos pronunciamientos, en razón a que algunos eran reiterativos y no presentaban ningún avance o desarrollo sobre lo que ya había establecido el Tribunal previamente. Los pronunciamientos con menor relevancia son los siguientes y la motivación de dicha decisión se ve en la tabla 3 . 
Tabla 3. Providencias rechazadas a partir de la aplicación del método censitario lato sensu

\begin{tabular}{|c|c|c|c|}
\hline \multicolumn{4}{|c|}{$\begin{array}{l}\text { Pronunciamiento de la Corte Constitucional frente al uso de la expresión "trabajo penitenciario y } \\
\text { trabajo carcelario" entre } 1992 \text { a } 2020 \text {, rechazados. }\end{array}$} \\
\hline Providencias & Contexto del caso concreto & Motivación de su rechazo & Puntuación \\
\hline C 580/96 & $\begin{array}{l}\text { Considera el actor que el artículo } 100 \text { de la } \\
\text { Ley } 65 \text { de } 1993 \text { infringe los artículos } 1,2,4, \\
13,25 \text { y } 53 \text { de la Constitución y el Convenio } \\
14 \text { de la ort. La razón es que se establece } \\
\text { una limitación a la redención de la pena } \\
\text { que es injusta y discriminatoria, pues al no } \\
\text { computársele al recluso para la redención } \\
\text { de la pena los días domingos y festivos, en } \\
\text { los cuales no se le permite trabajar, se le } \\
\text { desconocen } 52 \text { días al año en los cuales } \\
\text { pudiera trabajar. }\end{array}$ & $\begin{array}{l}\text { La Corte se limita a establecer } \\
\text { el fin resocializador del trabajo } \\
\text { penitenciario, lo cual ya había } \\
\text { sido desarrollado por esta } \\
\text { entidad previamente. }\end{array}$ & 1 \\
\hline C $1.510 / 00$ & $\begin{array}{l}\text { Considera el actor que los artículos } 80 \text { y } 81 \\
\text { de la Ley } 65 \text { de } 1993 \text { vulneran el artículo } 13 \\
\text { de la Constitución Política y el } 5.6 \text { de la Ley } \\
16 \text { de } 1972 \text {, aprobatoria de la Convención } \\
\text { Americana sobre Derechos Humanos. Esto } \\
\text { debido a que se discrimina a las personas } \\
\text { privadas de su libertad que cumplen con } \\
\text { su pena desde su domicilio, pues la norma } \\
\text { se refiere específicamente a las personas } \\
\text { recluidas en centros penitenciarios. }\end{array}$ & $\begin{array}{l}\text { La Corte no ahonda de mayor } \\
\text { forma el derecho al trabajo } \\
\text { penitenciario, sino que le da } \\
\text { una interpretación más amplia } \\
\text { a la norma, estableciendo que } \\
\text { la expresión cetro penitenciario } \\
\text { no es absoluta y que las } \\
\text { personas que cumplen su pena } \\
\text { desde su domicilio también } \\
\text { tienen derecho a laborar y } \\
\text { los cobija la misma normativa } \\
\text { que a las personas que se } \\
\text { encuentran recluida en centros } \\
\text { penitenciarios y carcelarios. }\end{array}$ & 0 \\
\hline Т $213 / 11$ & $\begin{array}{l}\text { Los accionantes, mediante escritos } \\
\text { separados, promovieron una acción de } \\
\text { tutela contra el Ministerio del Interior } \\
\text { y de Justicia, el Instituto Penitenciario y } \\
\text { Carcelario (Inpec) y el Establecimiento } \\
\text { Penitenciario y Carcelario Picaleña de } \\
\text { Ibagué. Esto se hace con el propósito } \\
\text { de obtener el amparo de sus derechos } \\
\text { fundamentales al trabajo, al debido } \\
\text { proceso y a la libertad, presuntamente } \\
\text { vulnerados con las omisiones y actuaciones } \\
\text { adelantadas por dichas entidades. Por } \\
\text { ejemplo, por un lado, se excluyó al señor } \\
\text { Edgardo Garid Grajales Grisales de } \\
\text { programas de redención de pena; por el } \\
\text { otro, se trasladó al señor Javier Alfredo } \\
\text { Pereira Garzón y otros internos de un } \\
\text { pabellón de Mediana Seguridad, y no } \\
\text { se incluyeron en programas de estudio, } \\
\text { trabajo o enseñanza que les permitan } \\
\text { redimir pena. }\end{array}$ & $\begin{array}{l}\text { La Corte no manifiesta } \\
\text { ningún avance frente al } \\
\text { derecho al trabajo en centros } \\
\text { penitenciarios, solo se limitó } \\
\text { a establecer la naturaleza del } \\
\text { mismo, siendo reiterativo en la } \\
\text { actual investigación. }\end{array}$ & 1 \\
\hline Auto $184 / 14$ & $\begin{array}{l}\text { Un grupo de reclusos del establecimiento } \\
\text { carcelario de mínima seguridad ubicado } \\
\text { en el municipio de El Socorro, Santander, } \\
\text { decide interponer una acción popular } \\
\text { contra el Inpec. Esto debido a que se } \\
\text { consideró que se les ha violentado el } \\
\text { derecho al trabajo, la igualdad y la libertad. }\end{array}$ & $\begin{array}{l}\text { La Corte se limitó a debatir si la } \\
\text { acción popular era el mecanismo } \\
\text { idóneo para la protección de } \\
\text { los derechos de los accionantes, } \\
\text { sin profundizar respecto al } \\
\text { derecho al trabajo en los centros } \\
\text { penitenciarios. }\end{array}$ & 0 \\
\hline
\end{tabular}




\begin{tabular}{|c|c|c|c|}
\hline T 718/15 & $\begin{array}{l}\text { El accionante promovió una acción de } \\
\text { tutela contra la Sala Penal del Tribunal } \\
\text { Superior de Popayán y el Juzgado Primero } \\
\text { de Ejecución de Penas y Medidas de } \\
\text { Seguridad de Popayán, al considerar } \\
\text { vulnerados sus derechos fundamentales } \\
\text { a la dignidad humana, a la igualdad y al } \\
\text { debido proceso. Asimismo, solicitó dejar } \\
\text { sin efecto la providencia, mediante la cual } \\
\text { la Sala Penal del Tribunal Superior de } \\
\text { Popayán revocó y negó la redención de } \\
\text { pena reconocida por el juez. }\end{array}$ & $\begin{array}{l}\text { La Corte delimitó su debate } \\
\text { en lo correspondiente a } \\
\text { la reducción de penas de } \\
\text { condenados por delitos contra } \\
\text { menores, sin realizar aporte al } \\
\text { tema base de esta investigación. }\end{array}$ & 0 \\
\hline $\mathrm{T} 100 / 18$ & $\begin{array}{l}\text { Alfredo Caldas Meneses interpuso } \\
\text { una acción de tutela contra Inpec, el } \\
\text { Establecimiento Penitenciario de Alta y } \\
\text { Mediana Seguridad de Girón y el Juzgado } \\
\text { Cuarto de Ejecución de Penas y Medidas } \\
\text { de Seguridad de Bucaramanga. Esto fue } \\
\text { por considerar vulnerados sus derechos } \\
\text { fundamentales a la igualdad, de libertad } \\
\text { de cultos, y a expresar y difundir sus } \\
\text { pensamientos. El demandante indicaba } \\
\text { que, a pesar de que profesa una religión } \\
\text { distinta de la católica, no puede trabajar } \\
\text { los días festivos propios de esa religión. }\end{array}$ & $\begin{array}{l}\text { La Corte se centró en establecer } \\
\text { si existía una vulneración al } \\
\text { derecho de libertad de cultos y } \\
\text { no en lo que respecta al derecho } \\
\text { al trabajo, por lo tanto, no hubo } \\
\text { mayor pronunciamiento frente a } \\
\text { lo que atañe esta investigación. }\end{array}$ & 1 \\
\hline C $254 / 19$ & $\begin{array}{l}\text { En cumplimiento de lo dispuesto en } \\
\text { el numeral } 10 \text { del artículo } 241 \text { de la } \\
\text { Constitución, la Secretaría Jurídica de } \\
\text { la Presidencia de la República remitió } \\
\text { copia auténtica del tratado, el Canje de } \\
\text { Notas y la ley aprobatoria. En desarrollo } \\
\text { de dicho mandato superior, el despacho } \\
\text { sustanciador, mediante auto de } 9 \text { de agosto } \\
\text { del 2017, dispuso i) avocar el conocimiento } \\
\text { del tratado y el Canje de Notas, así como de } \\
\text { la ley aprobatoria; ii) decretar la práctica } \\
\text { de pruebas; iii) comunicar la iniciación } \\
\text { del asunto al presidente de la República al } \\
\text { presidente del Congreso. }\end{array}$ & $\begin{array}{l}\text { En este pronunciamiento } \\
\text { únicamente se mencionan los } \\
\text { beneficios que trae el tratado } \\
\text { para el trabajo penitenciario, } \\
\text { pero estos no se discriminan, } \\
\text { ni mucho menos se hace un } \\
\text { desarrollo al derecho. }\end{array}$ & 0 \\
\hline
\end{tabular}

Fuente: elaboración propia.

Teniendo en cuenta lo expuesto, se procede a realizar el análisis de las sentencias del Tribunal que crean, desarrollan o eliminan alguna garantía referente al trabajo penitenciario. Este ejercicio se realizará en orden cronológico ascendente (tabla 4). 
Tabla 4. Evaluación de los pronunciamientos de la Corte Constitucional sobre la expresión "trabajo penitenciario y trabajo carcelario" entre 1992 y el 2020

\begin{tabular}{|c|c|c|c|}
\hline Providencia & Contexto del caso en concreto & Aporte & Puntos \\
\hline Т $601 / 92$ & $\begin{array}{l}\text { El accionante interpuso una } \\
\text { acción de tutela contra el Consejo } \\
\text { de Disciplina de la Penitenciaria } \\
\text { Peñas Blancas en razón a que } \\
\text { se le rebajó su calificación de } \\
\text { conducta ejemplar a regular, } \\
\text { con la suspensión del derecho } \\
\text { al trabajo y del permiso especial } \\
\text { para salir del penal por } 72 \text { horas, } \\
\text { respectivamente. } \\
\text { El petente alega la vulneración del } \\
\text { derecho fundamental al trabajo, ya } \\
\text { que manifiesta que la investigación } \\
\text { adelantada por la Dirección de } \\
\text { la Penitenciaría violó el debido } \\
\text { proceso. } \\
\text { La Corte estableció que la } \\
\text { decisión disciplinaria impuesta al } \\
\text { accionante vulneró sus derechos } \\
\text { a la defensa y al debido proceso } \\
\text { por carencia de comprobación } \\
\text { de los hechos sindicados. En } \\
\text { consecuencia, se revocó la } \\
\text { sentencia revisada. }\end{array}$ & $\begin{array}{l}\text { Ha establecido el tribunal que } \\
\text { El trabajo desarrollado por los } \\
\text { presos es un medio indispensable } \\
\text { para alcanzar el fin resocializador } \\
\text { de la pena y hace parte integrante } \\
\text { del núcleo esencial del derecho a } \\
\text { la libertad, pues tiene la virtud de } \\
\text { aminorar el tiempo de duración de la } \\
\text { pena a través de su rebaja o redención, } \\
\text { (Corte Constitucional, Sentencia } \\
\text { T 601, 1992). } \\
\text { Por tanto, es obligación del } \\
\text { Estado proveer a los reclusos } \\
\text { trabajos que contribuyan a su } \\
\text { readaptación social progresiva, a } \\
\text { la vez que permitan, en caso de } \\
\text { existir familia, el cumplimiento } \\
\text { de sus obligaciones alimentarias. } \\
\text { Los empleos deben asignarse } \\
\text { en condiciones de igualdad de } \\
\text { oportunidades, sin que el orden } \\
\text { de prelación pueda ser objeto } \\
\text { de una aplicación arbitraria } \\
\text { o discriminatoria (Const., } \\
\text { 1991, art. 13). Además de esto, } \\
\text { los reos tienen plena libertad } \\
\text { para escoger sobre la forma de } \\
\text { actividad que mejor consulte sus } \\
\text { aptitudes e inclinaciones, lo cual } \\
\text { es concordante con el derecho } \\
\text { fundamental de libertad de } \\
\text { escoger profesión u oficio (Const., } \\
\text { 1991, art. 13). }\end{array}$ & 4 \\
\hline Т 009/93 & $\begin{array}{l}\text { Los reclamantes interpusieron } \\
\text { una acción de tutela contra la } \\
\text { Cárcel Nacional Modelo, pues se } \\
\text { consideraban que se les estaban } \\
\text { vulnerando el derecho a la } \\
\text { igualdad, ya que, para la redención } \\
\text { de su pena por trabajo, estudio y } \\
\text { enseñanza no se incluyen los días } \\
\text { sábados, domingos y festivos, a } \\
\text { pesar de haber cumplido el recluso } \\
\text { con la jornada máxima de trabajo, } \\
\text { lo cual sí es permitido en otros } \\
\text { centros penitenciarios. } \\
\text { El tribunal determinó que existía } \\
\text { una interpretación errónea sobre } \\
\text { la norma, por lo cual no se les } \\
\text { estaba vulnerando el derecho a los } \\
\text { petendis. }\end{array}$ & $\begin{array}{l}\text { La Corte concluye que existe una } \\
\text { imposibilidad legal de asumir } \\
\text { como trabajados los días que } \\
\text { efectivamente no lo han sido, } \\
\text { ya que no puede confundirse la } \\
\text { garantía del descanso remunerado } \\
\text { en domingos y festivos con una } \\
\text { presunción no establecida por } \\
\text { el legislador que conduce a } \\
\text { entenderlos como días trabajados: } \\
\text { Carece de justificación constitucional } \\
\text { o legal la pretensión de otorgar el } \\
\text { carácter de laborados a los días de } \\
\text { descanso remunerado para efectos de } \\
\text { ser tenidos en cuenta en la redención } \\
\text { de pena. No debe confundirse la } \\
\text { naturaleza salarial y prestacional } \\
\text { de la garantía laboral del descanso } \\
\text { remunerado con una decisión } \\
\text { legislativa - hoy inexistente-, en } \\
\text { el sentido de otorgarle a dichos días } \\
\text { el carácter de laborados en materia } \\
\text { de ejecución de la pena (Corte } \\
\text { Constitucional, Sentencia T 009, } \\
\text { 1993). } \\
\text { El trabajo, en su triple naturaleza } \\
\text { constitucional, es un valor } \\
\text { fundante del régimen democrático }\end{array}$ & 3 \\
\hline
\end{tabular}




\begin{tabular}{|c|c|c|c|}
\hline Providencia & Contexto del caso en concreto & Aporte & Puntos \\
\hline & & $\begin{array}{l}\text { y del Estado Social de Derecho, } \\
\text { un derecho fundamental de } \\
\text { desarrollo legal estatutario y una } \\
\text { obligación social (Const., 1991, } \\
\text { arts. 1, 25, 53). } \\
\text { En materia punitiva, además, es } \\
\text { uno de los medios principales para } \\
\text { alcanzar la finalidad resocializadora } \\
\text { de la pena, ya que ofrece al infractor } \\
\text { la posibilidad de rehabilitarse } \\
\text { mediante el aprendizaje y la práctica } \\
\text { de labores económicamente } \\
\text { productivas, las cuales pueden abrirle } \\
\text { nuevas oportunidades en el futuro y } \\
\text { conservar así la esperanza de libertad, } \\
\text { (Corte Constitucional, Sentencia T } \\
\text { 009, 1993). } \\
\text { El fin resocializador de la pena } \\
\text { tiene la función de formar al } \\
\text { interno en el uso responsable de } \\
\text { su libertad. Esto es posible a través } \\
\text { del trabajo, mediante el respeto } \\
\text { de sus garantías constitucionales y } \\
\text { legales. Sin el descanso necesario } \\
\text { y el reconocimiento salarial } \\
\text { correspondiente, la efectividad } \\
\text { de este medio se vería menguada } \\
\text { (Const., 1991). }\end{array}$ & \\
\hline Т $121 / 93$ & $\begin{array}{l}\text { El peticionario hizo ejercicio de su } \\
\text { derecho, entablando una acción } \\
\text { de tutela contra la Cárcel Nacional } \\
\text { Modelo, alegando que el cálculo } \\
\text { para la redención de su pena no } \\
\text { corresponde a la realidad, pues no } \\
\text { fueron computadas todas sus horas } \\
\text { de trabajo. } \\
\text { La Corte determinó que } \\
\text { efectivamente no se computó } \\
\text { correctamente y debía corregirse, } \\
\text { ya que los detenidos que laboren } \\
\text { los días domingos o feriados } \\
\text { tendrán derecho a que se les } \\
\text { certifique el tiempo laborado, sin } \\
\text { exceder de ocho horas diarias, así } \\
\text { coincidan con los días de visitas } \\
\text { determinados en cada centro de } \\
\text { reclusión. }\end{array}$ & $\begin{array}{l}\text { El trabajo, en el caso de los } \\
\text { establecimientos carcelarios, } \\
\text { es, además de un instrumento } \\
\text { resocializador, un mecanismo } \\
\text { tendiente a lograr la paz. En otras } \\
\text { palabras, tiene una doble función: } \\
\text { no solo permite que el detenido } \\
\text { pueda rehabilitarse por medio } \\
\text { del ejercicio de una actividad } \\
\text { económicamente productiva, } \\
\text { sino que inclusive sirve para } \\
\text { impedir que el infractor de la } \\
\text { ley pueda incurrir en nuevos } \\
\text { hechos punibles o, en todo caso, } \\
\text { en conductas que, al menos } \\
\text { durante el tiempo de reclusión, } \\
\text { conlleven al ocio y la vagancia que } \\
\text { tantos males originan en la vida } \\
\text { carcelaria. }\end{array}$ & 2 \\
\hline C $394 / 95$ & $\begin{array}{l}\text { El actor sostiene que resultan } \\
\text { inconstitucionales varias de las } \\
\text { facultades que la ley } 65 \text { de } 1993 \\
\text { otorga al director del Inpec y a } \\
\text { los directores de establecimientos } \\
\text { carcelarios, ya que estas deberían } \\
\text { ser ejecutadas por el legislador en } \\
\text { razón a los derechos que regula. } \\
\text { La Corte establece que el derecho } \\
\text { al trabajo consiste en una facultad } \\
\text { perfeccionante sobre las cosas, y } \\
\text { no en una potestad omnímoda que } \\
\text { pueda contravenir los intereses de } \\
\text { la sociedad. } \\
\text { Todo establecimiento carcelario } \\
\text { debe tener un horario que } \\
\text { establezca las oportunidades de }\end{array}$ & $\begin{array}{l}\text { En el ejercicio del trabajo } \\
\text { penitenciario con particulares, se } \\
\text { debe contratar directamente con } \\
\text { la administración de cada centro } \\
\text { de reclusión o con la Sociedad } \\
\text { Renacimiento. Los reclusos no } \\
\text { están facultados para establecer } \\
\text { una relación de trabajo por sí } \\
\text { mismos. Sin embargo, en el } \\
\text { caso concreto de los contratos } \\
\text { de trabajo, la Corte advierte } \\
\text { que en principio el trabajo } \\
\text { realizado por los internos en los } \\
\text { centros de reclusión consiste en } \\
\text { una prestación de servicios de } \\
\text { naturaleza civil, en el cual no } \\
\text { existe propiamente relación de } \\
\text { subordinación, más aún cuando }\end{array}$ & 3 \\
\hline
\end{tabular}




\begin{tabular}{|c|c|c|c|}
\hline Providencia & Contexto del caso en concreto & Aporte & Puntos \\
\hline & $\begin{array}{l}\text { realizar las diversas actividades } \\
\text { y para ello están facultadas sus } \\
\text { directivas, no por capricho de } \\
\text { estas, sino por mandato de la ley. } \\
\text { Sería absurdo que el Congreso } \\
\text { tuviese que expedir una ley para } \\
\text { cada reglamento interno de } \\
\text { trabajo. }\end{array}$ & $\begin{array}{l}\text { no se configura un contrato de } \\
\text { trabajo entre el interno y un } \\
\text { patrono, ni ceden, por ende, los } \\
\text { elementos que tipifican dicho } \\
\text { contrato. } \\
\text { En la eventualidad de que se } \\
\text { configurara la continuada } \\
\text { subordinación o dependencia } \\
\text { del trabajador respecto del } \\
\text { empleador, habría lugar al pago } \\
\text { de un salario proporcional } \\
\text { equivalente al número de horas } \\
\text { trabajadas, con base en el salario } \\
\text { mínimo legal vigente. Por lo } \\
\text { demás, en los casos en que un } \\
\text { recluso trabajase al servicio de } \\
\text { un particular bajo alguna de las } \\
\text { modalidades permitidas legal o } \\
\text { reglamentariamente, esta relación } \\
\text { deberá regirse por las normas } \\
\text { laborales vigentes. }\end{array}$ & \\
\hline Т $1.190 / 03$ & $\begin{array}{l}\text { El recurrente interpuso una acción } \\
\text { de tutela contra la Penitenciaría } \\
\text { Nacional de Valledupar, pues } \\
\text { considera que al carecer de } \\
\text { oportunidades para el desarrollo } \\
\text { de actividades productivas han } \\
\text { sido vulnerados sus derechos } \\
\text { fundamentales al trabajo, a la } \\
\text { igualdad y a la vida digna. } \\
\text { La Corte impone como medida } \\
\text { necesaria que las autoridades del } \\
\text { penal reconsideren la solicitud del } \\
\text { interno y valoren nuevamente su } \\
\text { solicitud de trabajo, teniendo en } \\
\text { cuenta el estado actual del proceso } \\
\text { de resocialización del interno, } \\
\text { su situación concreta y los demás } \\
\text { factores que ordinariamente } \\
\text { deben ser valorados en este tipo de } \\
\text { casos, sobre todo el derecho a la } \\
\text { igualdad respecto de la situación } \\
\text { de los demás internos. }\end{array}$ & $\begin{array}{l}\text { El proceso de resocialización } \\
\text { está edificado sobre un conjunto } \\
\text { de factores que deben concurrir } \\
\text { para garantizar las condiciones } \\
\text { necesarias para su eficacia: (i) } \\
\text { la oportunidad y disposición } \\
\text { permanente de medios que } \\
\text { garanticen la realización de } \\
\text { diversas actividades de orden } \\
\text { laboral, educativo, deportivo } \\
\text { y lúdico; (ii) las condiciones } \\
\text { cualificadas de reclusión, } \\
\text { en aspectos básicos como el } \\
\text { goce permanente de servicios } \\
\text { públicos esenciales, buenas } \\
\text { condiciones de alojamiento, } \\
\text { alimentación balanceada, } \\
\text { servicios sanitarios mínimos, } \\
\text { etc., y (iii) el acompañamiento } \\
\text { permanente durante el periodo } \\
\text { en que se prolonga la privación } \\
\text { de la libertad, con el auxilio de } \\
\text { un equipo interdisciplinario de } \\
\text { profesionales en ciencias sociales y } \\
\text { de la salud, de la red de apoyo y de } \\
\text { la familia del recluso. } \\
\text { El proceso de resocialización } \\
\text { es impensable o mucho más } \\
\text { adverso sin el concurso activo y } \\
\text { la presencia constante del grupo } \\
\text { familiar. Esto se explica por varias } \\
\text { razones. La familia es el único } \\
\text { referente seguro de libertad } \\
\text { con el que cuentan las personas } \\
\text { recluidas; la mejor forma de } \\
\text { mantener contacto con la sociedad } \\
\text { y con el mundo fuera del penal, } \\
\text { y, sobre todo, constituye el centro } \\
\text { de los vínculos afectivos más } \\
\text { importante y duradero. Esto le } \\
\text { permite al recluso sobreponerse } \\
\text { a sus condiciones de penuria y } \\
\text { guardar esperanzas para la }\end{array}$ & 4 \\
\hline
\end{tabular}




\begin{tabular}{|c|c|c|c|}
\hline \multirow[t]{2}{*}{ Providencia } & Contexto del caso en concreto & Aporte & Puntos \\
\hline & & $\begin{array}{l}\text { libertad. Sin estos elementos es } \\
\text { bastante difícil que se realice en } \\
\text { una medida razonable el propósito } \\
\text { de resocialización. El Tribunal } \\
\text { advierte que, en el presente caso, } \\
\text { las posibilidades de ejercicio } \\
\text { de este derecho se tornan en } \\
\text { condiciones necesarias para el } \\
\text { ejercicio de otro derecho como es } \\
\text { el de mantener un contacto más } \\
\text { cercano con los miembros de su } \\
\text { familia. }\end{array}$ & \\
\hline T $1.077 / 05$ & $\begin{array}{l}\text { El recurrente interpuso una acción } \\
\text { de tutela contra el Establecimiento } \\
\text { Penitenciario y Carcelario de alta y } \\
\text { mediana seguridad de La Dorada, } \\
\text { porque considera que se le está } \\
\text { vulnerando su derecho al trabajo } \\
\text { y al mínimo vital. Las labores } \\
\text { que desempeñó como aseador } \\
\text { solo se tuvieron en cuenta para la } \\
\text { redención de la pena y no fueron } \\
\text { bonificadas económicamente. } \\
\text { Ante la ausencia de vulneración } \\
\text { de los derechos fundamentales } \\
\text { invocados por los reclusos, la } \\
\text { Sala confirma las decisiones de } \\
\text { instancia que negaron el amparo } \\
\text { constitucional solicitado. }\end{array}$ & 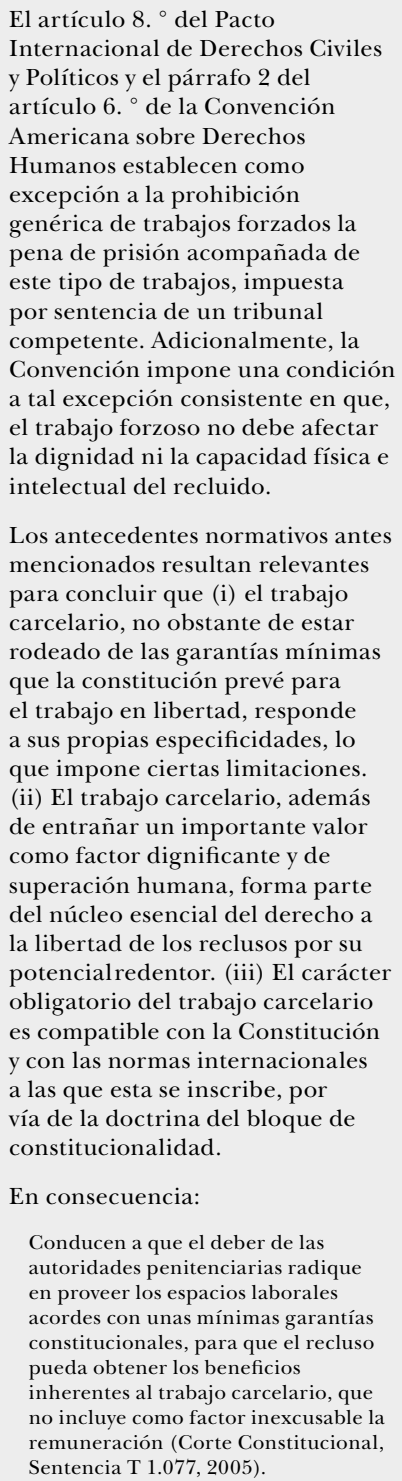 & 3 \\
\hline
\end{tabular}




\begin{tabular}{|c|c|c|c|}
\hline \multirow[t]{2}{*}{ Providencia } & Contexto del caso en concreto & Aporte & Puntos \\
\hline & & $\begin{array}{l}\text { Se entiende, entonces, que el } \\
\text { salario no es parte fundamental } \\
\text { del derecho al trabajo en } \\
\text { los centros penitenciarios y } \\
\text { carcelarios. }\end{array}$ & \\
\hline Т $1.303 / 05$ & $\begin{array}{l}\text { El demandante radica una } \\
\text { tutela contra el Establecimiento } \\
\text { Penitenciario y Carcelario de alta y } \\
\text { mediana seguridad de la Dorada. } \\
\text { Este indica que le fue vulnerado } \\
\text { su derecho al debido proceso y al } \\
\text { trabajo penitenciario, ya que fue } \\
\text { suspendida su orden de trabajo } \\
\text { para laborar como ranchero. Se } \\
\text { aducía había incurrido en una } \\
\text { causal disciplinaria. } \\
\text { Al realizar el análisis } \\
\text { correspondiente a los hechos del } \\
\text { caso, el Tribunal declaró que se } \\
\text { presentó una violación de los } \\
\text { derechos del accionante, pues el } \\
\text { proceso por medio del cual se le } \\
\text { suspendió el permiso de trabajo } \\
\text { no cumplió con las garantías del } \\
\text { debido proceso. }\end{array}$ & $\begin{array}{l}\text { La jurisprudencia de la Corte } \\
\text { ha indicado que el Estado tiene } \\
\text { deberes especiales con los } \\
\text { reclusos, con miras a que estos } \\
\text { puedan ejercer plenamente los } \\
\text { derechos fundamentales que } \\
\text { no les han sido suspendidos, y } \\
\text { parcialmente aquellos que les han } \\
\text { sido restringidos }{ }^{11} \text {. Estos deberes } \\
\text { no implican simplemente que } \\
\text { el Estado no deba interferir en } \\
\text { la esfera de desarrollo de estos } \\
\text { derechos, sino también que el } \\
\text { Estado debe ponerse en acción } \\
\text { para garantizarles a los internos } \\
\text { el pleno goce de otros derechos, } \\
\text { tales como la dignidad, la salud, la } \\
\text { alimentación, el trabajo, etc. Esta } \\
\text { conclusión se deriva de la misma } \\
\text { relación especial de sujeción de } \\
\text { los penados frente al Estado y } \\
\text { del hecho de que las condiciones } \\
\text { que se imponen a los reclusos } \\
\text { les impide que puedan satisfacer } \\
\text { por cuenta propia una serie } \\
\text { de necesidades mínimas, cuya } \\
\text { atención garantiza la posibilidad } \\
\text { de llevar una vida digna (Corte } \\
\text { Constitucional, Sentencia T } 153, \\
\text { 1998). } \\
\text { En suma, la reclusión de una } \\
\text { persona apareja el surgimiento de } \\
\text { una serie de deberes especiales } \\
\text { a cargo del Estado, con el fin de } \\
\text { que el interno pueda realizar } \\
\text { efectivamente los derechos que } \\
\text { no le han sido formalmente } \\
\text { suspendidos ni limitados, pero } \\
\text { cuyo ejercicio resulta imposible sin } \\
\text { la colaboración activa del Estado, } \\
\text { (Corte Constitucional, Sentencia T } \\
\text { 966, 2001). } \\
\text { En virtud del papel relevante que } \\
\text { cumple el trabajo penitenciario } \\
\text { en los fines de la pena, en } \\
\text { particular la resocialización y la } \\
\text { materialización del derecho a la } \\
\text { libertad, el sistema penitenciario } \\
\text { radica en las autoridades } \\
\text { acnitenciarias unos deberes de } \\
\text { de este derecho. En cuanto a }\end{array}$ & 2 \\
\hline
\end{tabular}

11 Acerca de los deberes especiales del Estado para con los reclusos véanse, entre otras, sentencia T 522 (1992); sentencia T 374 (1993); sentencia T 388 (1993); sentencia T 420 (1994); sentencia T 741, 2004. 


\begin{tabular}{|c|c|c|c|}
\hline Providencia & Contexto del caso en concreto & Aporte & Puntos \\
\hline & & $\begin{array}{l}\text { lo primero, las mencionadas } \\
\text { autoridades están obligadas a } \\
\text { crear espacios que garanticen, } \\
\text { promuevan y hagan posible el } \\
\text { acceso a fuentes de trabajo de } \\
\text { manera que se materialice el } \\
\text { carácter imperativo del trabajo } \\
\text { penitenciario (Ley } 65,1993 \text { ). } \\
\text { Frente a lo segundo, se trata de un } \\
\text { derecho en el cual las autoridades } \\
\text { penitenciarias se deben abstener } \\
\text { de actos vulneratorios. La } \\
\text { protección que el propio régimen } \\
\text { penitenciario prodiga a este } \\
\text { derecho de los reclusos impide } \\
\text { a las autoridades penitenciarias } \\
\text { aplicar a su arbitrio y de manera } \\
\text { discrecional mecanismos como } \\
\text { la cancelación de órdenes de } \\
\text { trabajo como respuesta retalitiva a } \\
\text { comportamientos de los reclusos } \\
\text { que consideren impropios. } \\
\text { Conforme a este régimen, se } \\
\text { trata de un derecho que solo } \\
\text { puede ser restringido mediante } \\
\text { el agotamiento previo de un } \\
\text { proceso disciplinario en el que se } \\
\text { preserven todas las garantías que } \\
\text { les son propias. }\end{array}$ & \\
\hline $\mathrm{T} 429 / 10$ & $\begin{array}{l}\text { El actor interpuso una acción } \\
\text { de tutela contra el director } \\
\text { de la Penitenciaría de Alta y } \\
\text { Mediana Seguridad de Palogordo, } \\
\text { Girón, por considerar que } \\
\text { este conculcaba sus derechos } \\
\text { fundamentales a la igualdad y al } \\
\text { trabajo. La razón era que la labor } \\
\text { desempeñada por este no estaba } \\
\text { contemplada dentro de la circular } \\
\text { 032 del } 2006 \text { como actividad a } \\
\text { bonificar. El Tribunal coincide } \\
\text { con el accionante, alegando } \\
\text { que, debido al reconocimiento y } \\
\text { protección del derecho al trabajo } \\
\text { en Colombia, en todas sus formas } \\
\text { este siempre debe remunerarse de } \\
\text { manera equitativa, sin distinción } \\
\text { alguna. }\end{array}$ & $\begin{array}{l}\text { El artículo } 86 \text { del Código } \\
\text { Penitenciario y Carcelario } \\
\text { prescribe que el trabajo de } \\
\text { los reclusos se remunerará de } \\
\text { una manera equitativa, sin } \\
\text { distinguir si se trata del trabajo } \\
\text { prestado por intermedio del } \\
\text { Inpec a particulares o si versa } \\
\text { sobre las labores desarrolladas } \\
\text { directamente bajo la coordinación } \\
\text { del Estado. } \\
\text { Adicionalmente, esta disposición } \\
\text { consagra que el trabajo habrá } \\
\text { de desarrollarse dentro de un } \\
\text { ambiente adecuado y bajo la } \\
\text { observación de las normas de } \\
\text { seguridad industrial (Convenio } \\
\text { sobre el trabajo forzoso, 1930). } \\
\text { En cuanto a la protección social } \\
\text { y laboral de los reclusos, se } \\
\text { contempla que será precisada } \\
\text { dentro del reglamento general } \\
\text { e interno de cada centro de } \\
\text { reclusión; que debe sujetarse al } \\
\text { reglamento general del Inpec y } \\
\text { ser compatible con los convenios y } \\
\text { tratados internacionales suscritos } \\
\text { y ratificados por Colombia, así } \\
\text { como las demás normas laborales } \\
\text { que contempla el Código } \\
\text { Penitenciario y Carcelario, como } \\
\text { la protección laboral y social o las } \\
\text { indemnizaciones por accidentes } \\
\text { de trabajo, (Corte Constitucional, } \\
\text { Sentencia T 429, 2012). }\end{array}$ & 5 \\
\hline
\end{tabular}




\begin{tabular}{|c|c|c|c|}
\hline Providencia & Contexto del caso en concreto & Aporte & Puntos \\
\hline & & $\begin{array}{l}\text { Es necesario recordar que el } \\
\text { trabajo penitenciario no deviene } \\
\text { de un contrato laboral, sino de } \\
\text { una relación de derecho público } \\
\text { que surge como consecuencia } \\
\text { de la pena. Sin embargo, la } \\
\text { remuneración tampoco puede } \\
\text { conllevar a una precaria } \\
\text { "salarización" que acarree la } \\
\text { explotación institucionalizada } \\
\text { del recluso, pues esto sería } \\
\text { contrario a la dignidad humana. } \\
\text { Por lo mismo, bastaría entonces, } \\
\text { conforme con las normas } \\
\text { nacionales e internacionales, } \\
\text { que se fijen criterios de equidad } \\
\text { para determinar el monto de las } \\
\text { mencionadas bonificaciones. Dado } \\
\text { que el tratamiento penitenciario } \\
\text { es un sistema progresivo, deben } \\
\text { aumentar paulatinamente según } \\
\text { la persona se vaya resocializando. } \\
\text { No obstante, la Constitución } \\
\text { protege el trabajo en todas sus } \\
\text { modalidades y los convenios } \\
\text { internacionales, así como la } \\
\text { legislación interna, expresamente } \\
\text { se refieren al derecho de los } \\
\text { reclusos de recibir remuneración } \\
\text { equitativa sin distinción alguna. } \\
\text { Por esta razón, la Sala estima que } \\
\text { el trabajo penitenciario debe ser } \\
\text { retribuido también mediante } \\
\text { el pago de una bonificación. } \\
\text { Esto debido a que este pago, por } \\
\text { servirse de la fuerza de trabajo de } \\
\text { un sujeto privado de la libertad, } \\
\text { hace parte de la esfera de bienes } \\
\text { intangibles de la población } \\
\text { reclusa. }\end{array}$ & \\
\hline T 286/11 & $\begin{array}{l}\text { El demandante acudió ante el } \\
\text { juez de tutela la protección de } \\
\text { sus derechos fundamentales de } \\
\text { petición, al trabajo y a la igualdad, } \\
\text { presuntamente vulnerados por } \\
\text { el director y el jefe de la Oficina } \\
\text { de Tratamiento y Desarrollo del } \\
\text { Establecimiento Penitenciario y } \\
\text { Carcelario Picaleña de Ibagué. } \\
\text { Esto ocurrió por cuanto en dicho } \\
\text { centro de reclusión no se le ha } \\
\text { permitido realizar actividades de } \\
\text { trabajo o estudio para efectos de } \\
\text { redimir su pena, aduciendo que } \\
\text { por tener la calidad de sindicado } \\
\text { no es sujeto de tratamiento } \\
\text { penitenciario. }\end{array}$ & $\begin{array}{l}\text { En resumen, el tratamiento } \\
\text { penitenciario está } \\
\text { predominantemente dirigido a } \\
\text { las personas que se encuentran } \\
\text { condenadas a pagar una pena. Sin } \\
\text { embargo, el Inpec tiene el deber } \\
\text { de brindar una atención integral } \\
\text { a todos los internos, sin importar } \\
\text { la situación jurídica de quienes } \\
\text { se encuentren en los centros } \\
\text { de reclusión, en su calidad de } \\
\text { sindicados. } \\
\text { El trabajo en un Centro Penitenciario } \\
\text { tiene el carácter de obligatorio solo } \\
\text { para los internos que tienen la calidad } \\
\text { de condenados. Sin embargo, dichas } \\
\text { labores pueden ser desarrolladas } \\
\text { por los internos del centro de } \\
\text { reclusión atendiendo sus aptitudes y } \\
\text { capacidades (Corte Constitucional, } \\
\text { Sentencia C } 1.510,2000)^{12} \text {. }\end{array}$ & 4 \\
\hline
\end{tabular}

12 La expresión centro de reclusión fue declarada exequible por la Corte Constitucional en la sentencia. Siempre y cuando se interpretara que dicho enunciado también comprendía el 


\begin{tabular}{|c|c|c|c|}
\hline \multirow[t]{2}{*}{ Providencia } & Contexto del caso en concreto & Aporte & Puntos \\
\hline & & $\begin{array}{l}\text { Si bien en términos materiales } \\
\text { es imposible garantizar a toda la } \\
\text { población carcelaria la asignación } \\
\text { de un puesto de trabajo al } \\
\text { tratarse de un bien escaso (Corte } \\
\text { Constitucional, Sentencia T } \\
\text { 1.190, 2003), también lo es que } \\
\text { la distribución de dichas labores } \\
\text { no puede realizarse con base en } \\
\text { parámetros discriminatorios ni } \\
\text { autoritarios, sino que debe mediar } \\
\text { una justificación constitucional } \\
\text { y legal que la respalde (Corte } \\
\text { Suprema de Justicia, Sala de } \\
\text { Casación Penal, Sentencia No. } \\
\text { 22777, 2004). }\end{array}$ & \\
\hline Т $865 / 12$ & $\begin{array}{l}\text { El aspirante interpuso una acción } \\
\text { de tutela contra el director } \\
\text { del establecimiento carcelario } \\
\text { de Manizales, por la presunta } \\
\text { vulneración de sus derechos } \\
\text { fundamentales de petición y al } \\
\text { trabajo, ya que este presentó un } \\
\text { derecho de petición. A través } \\
\text { de este solicitó al director } \\
\text { del centro de reclusión de } \\
\text { Manizales el reconocimiento de } \\
\text { las bonificaciones que, asegura, } \\
\text { tiene derecho por el trabajo } \\
\text { desempeñado como bibliotecario. } \\
\text { No obstante, transcurrido el } \\
\text { término legal previsto para la } \\
\text { respuesta al derecho de petición, } \\
\text { el accionante no recibió respuesta. } \\
\text { A partir de esto la Corte decidió } \\
\text { tutelar el derecho del accionante, } \\
\text { ordenando el pago de sus } \\
\text { acreencias. }\end{array}$ & $\begin{array}{l}\text { El artículo } 3 .^{\circ} \text { del Código } \\
\text { Penitenciario y Carcelario prohíbe } \\
\text { toda forma de discriminación } \\
\text { por razones de sexo, raza, origen } \\
\text { nacional o familiar, opinión } \\
\text { política o filosófica de los reclusos. } \\
\text { Empero, reconoce la posibilidad } \\
\text { de realizar algunas distinciones } \\
\text { por motivos de seguridad, } \\
\text { de resocialización o para el } \\
\text { cumplimiento de la sentencia } \\
\text { y de la política penitenciaria y } \\
\text { carcelaria. En este sentido, las } \\
\text { limitaciones a las que se somete } \\
\text { el derecho al trabajo de las } \\
\text { personas privadas de la libertad } \\
\text { dependen directamente de la } \\
\text { específica relación de sujeción } \\
\text { o subordinación en la que se } \\
\text { encuentran. No obstante: } \\
\text { Estas limitaciones no pueden tornarse } \\
\text { en medidas discriminatorias, } \\
\text { desproporcionadas o arbitrarias, por } \\
\text { el contrario, deben ser justificadas } \\
\text { desde el punto de vista legal y } \\
\text { constitucional, además de ser } \\
\text { razonables y proporcionales (Corte } \\
\text { Constitucional, Sentencia T } 865 \text {, } \\
\text { 2012). } \\
\text { Respecto de la protección laboral } \\
\text { y social, el artículo } 79 \text { del Código } \\
\text { Penitenciario y Carcelario dispone } \\
\text { que la protección laboral y social } \\
\text { de los reclusos se precisará en el } \\
\text { reglamento general e interno de } \\
\text { cada centro de reclusión (Ley } 65 \text {, } \\
\text { 1993). Ese artículo prescribe que } \\
\text { en el evento de sufrir un accidente } \\
\text { de trabajo, los reclusos gozarán } \\
\text { del derecho a las indemnizaciones } \\
\text { establecidas por la ley, y añade } \\
\text { que los detenidos podrán trabajar } \\
\text { individualmente o en grupos } \\
\text { de labores públicas, agrícolas o } \\
\text { industriales en las mismas }\end{array}$ & \\
\hline
\end{tabular}

domicilio o lugar de trabajo, cuando se concedía detención domiciliaria o detención parcial. 


\begin{tabular}{|c|c|c|}
\hline Providencia & Contexto del caso en concreto & Aporte \\
\hline & & $\begin{array}{l}\text { condiciones que los condenados. } \\
\text { Esto ocurrirá siempre que } \\
\text { el director del respectivo } \\
\text { establecimiento penal } \\
\text { conceda esta gracia, según las } \\
\text { consideraciones de conducta del } \\
\text { interno, calificación del delito y de } \\
\text { seguridad. } \\
\text { Es un deber del Estado, en } \\
\text { consecuencia, conseguir los } \\
\text { recursos económicos suficientes } \\
\text { para la efectiva resocialización } \\
\text { de los reclusos. De lo contrario, } \\
\text { no solo se desconocería lo } \\
\text { dispuesto por la Constitución } \\
\text { y por los tratados y convenios } \\
\text { internacionales sobre la materia, } \\
\text { sino que se pondría en entredicho } \\
\text { cualquier esfuerzo orientado a } \\
\text { obtener de manera real y efectiva } \\
\text { la resocialización de los reclusos. } \\
\text { No es, por tanto, suficiente } \\
\text { combatir los delitos con políticas } \\
\text { de seguridad: es preciso diseñar } \\
\text { un sistema que logre disuadir } \\
\text { a los delincuentes, de tal forma } \\
\text { que encuentren una motivación } \\
\text { distinta al crimen para sus } \\
\text { vidas y puedan participar libres } \\
\text { en la vida social aportando de } \\
\text { manera creativa, constructiva y } \\
\text { solidaria todo lo que son capaces } \\
\text { de aportar. La garantía de que } \\
\text { los internos puedan realizar un } \\
\text { trabajo en condiciones dignas y } \\
\text { justas cumple en relación con esta } \\
\text { esperanza un papel fundamental, } \\
\text { (Corte Constitucional, Sentencia T } \\
865,2012)^{13} \text {. }\end{array}$ \\
\hline
\end{tabular}

13 El decreto 1.758 (2015) dispuso que para los efectos de dicha reglamentación se entenderá como accidente de trabajo y enfermedad laboral aquellos eventos contemplados en la Ley 1.562 del 2012. Esta, a su vez, en sus artículos $3 .^{\circ}$ y $4 .^{\circ}$ consagra lo siguiente:

1) Es accidente de trabajo todo suceso repentino que sobrevenga por causa o con ocasión del trabajo del trabajo, y que produzca en el trabajador una lesión orgánica, una perturbación funcional o psiquiátrica, una invalidez o la muerte. Es también accidente de trabajo aquel que se produce durante la ejecución de órdenes del empleador, o contratante durante la ejecución de una labor bajo su autoridad, aún fuera del lugar y horas de trabajo. Igualmente se considera accidente de trabajo el que se produzca durante el traslado de los trabajadores o contratistas desde su residencia a los lugares de trabajo o viceversa, cuando el transporte lo suministre el empleador. También se considerará como accidente de trabajo el ocurrido durante el ejercicio de la función sindical, aunque el trabajador se encuentre en permiso sindical siempre que el accidente se produzca en cumplimiento de dicha función. De igual forma se considera accidente de trabajo el que se produzca por la ejecución de actividades recreativas, deportivas o culturales, cuando se actúe por cuenta o en representación del empleador o de la empresa usuaria cuando se trate de trabajadores de empresas de servicios temporales que se encuentren en misión. Y 2) Es enfermedad laboral la contraída como resultado de la exposición a factores de riesgo inherentes a la actividad laboral o del medio en el que el trabajador se ha visto obligado a trabajar. El Gobierno nacional determinará, en forma periódica, 


\begin{tabular}{|c|c|c|c|}
\hline Providencia & Contexto del caso en concreto & Aporte & Puntos \\
\hline & & $\begin{array}{l}\text { Las cotizaciones tendrán que ser } \\
\text { asumidas por el Inpec cuando } \\
\text { los internos presten sus servicios } \\
\text { directamente al instituto. En } \\
\text { el evento en el que el trabajo } \\
\text { penitenciario surja con ocasión } \\
\text { de un convenio con una persona } \\
\text { pública o privada, } \\
\text { El Inpec deberá garantizar que } \\
\text { dentro del mismo [sic] se incluyan } \\
\text { las obligaciones para la cancelación } \\
\text { de las sumas que corresponden a la } \\
\text { afiliación respectiva (Decreto 1758, } \\
\text { 2015, art 2.2.1.10.2.3) } \\
\text { La remuneración de las } \\
\text { incapacidades hace referencia } \\
\text { a aquellas que se dan cuando el } \\
\text { interno, durante el desempeño } \\
\text { del trabajo penitenciario, tenga } \\
\text { un accidente o una enfermedad } \\
\text { que le genere una incapacidad } \\
\text { certificada por el médico del } \\
\text { establecimiento carcelario o de la } \\
\text { entidad prestadora de salud. Sobre } \\
\text { esto el artículo } 27 \text { de la Resolución } \\
\text { 3.190 del } 2013 \text { establece (i) que } \\
\text { esta se pagará únicamente por } \\
\text { el periodo de la incapacidad, } \\
\text { máximo por } 30 \text { días, y (ii) que } \\
\text { debe ser asumida por el Inpec de } \\
\text { acuerdo con su disponibilidad } \\
\text { presupuestal o por el contratista. } \\
\text { Esto último depende de quien } \\
\text { ofrezca la plaza de trabajol4. } \\
\text { También se tiene en cuenta que, si } \\
\text { la incapacidad supera los } 30 \text { días o } \\
\text { el interno sufre un accidente: } \\
\text { Debe ser valorado por el médico del } \\
\text { Establecimiento, quien mediante } \\
\text { concepto determinará si puede } \\
\text { continuar en la actividad ocupacional } \\
\text { y lo remitiáa a la Junta de Evaluación, } \\
\text { Trabajo, Estudio y Enseñanza } \\
\text { quien determinará su reubicación } \\
\text { ocupacional (Resolución } 3.190,2013 \text { ). } \\
\text { Respecto a la protección de los } \\
\text { riesgos laborales }{ }^{14} \text { ocasionados por } \\
\text { accidentes de trabajo y }\end{array}$ & \\
\hline
\end{tabular}

las enfermedades que se consideran como laborales y en los casos en que una enfermedad no figure en la tabla de enfermedades laborales, pero se demuestre la relación de causalidad con los factores de riesgo ocupacional será reconocida como enfermedad laboral, conforme lo establecido en las normas legales vigentes (arts. $2.2 .1 .10 .5 .3)$.

14 Riesgos Laborales. Todas las personas privadas de la libertad que desarrollen actividades laborales deben estar afiliadas al Sistema General de Riesgos Laborales. [A su vez, dicho Sistema es] el conjunto de entidades públicas y privadas, normas y procedimientos, destinados a prevenir, proteger y atender a los trabajadores de los efectos de las enfermedades y los accidentes que puedan ocurrirles con ocasión o como consecuencia del trabajo que desarrollan. Las disposiciones vigentes de salud ocupacional relacionadas con la prevención de los accidentes de trabajo y enfermedades laborales y el mejoramiento de las condiciones de trabajo, hacen parte integrante del Sistema General de Riesgos Laborales (Decreto 1.758, 2015, arts 2.2.1.10.2.3). 
enfermedades laborales, cabe resaltar que (i) todas las personas privadas de la libertad que ejecuten un trabajo penitenciario deben estar afiliadas al Sistema General de Riesgos Laborales, y (ii) las cotizaciones tendrán que ser asumidas por el Inpec cuando los internos presten sus servicios directamente al instituto, o en el evento en el que el trabajo penitenciario surja con ocasión de un convenio con una persona pública o privada: "[...] el Inpec deberá garantizar que dentro del mismo se incluyan las obligaciones para la cancelación de las sumas que corresponden a la afiliación respectiva" (Decreto 1.758, 2015).

Por otra parte, la legislación ha establecido que el trabajo penitenciario no se llevará a cabo los días domingos y festivos. Sin embargo, en casos especiales debidamente autorizados y justificados por el director del establecimiento, las horas de trabajo en estos días se computan como ordinarias (Ley 65, 1993). En consecuencia, conforme lo ha sostenido la Corte:

Debe reconocerse el trabajo realizado por el interno en días dominicales y festivos, pero siempre y cuando la labor no exceda de ocho (8) horas diarias y sea autorizada por la autoridad competente y certificada por el director de la cárcel para efectos de la redención de la pena (Corte Constitucional, Sentencia T 121, 1993).

En el mismo sentido, la Corte Suprema de Justicia explicó lo siguiente:

De tiempo atrás en los establecimientos carcelarios se viene afirmando que esta Corporación, con ponencia de quien en este caso realiza idéntica labor, con fecha 24 de mayo de 1983, dispuso que los días domingos y festivos debían ser computados en forma triple, lo cual resulta inexacto, ya que la Corte en ningún momento ha afirmado lo que se predica y tampoco produjo en esa fecha, ni en ninguna otra, providencia sobre el tema y en los términos que aduce el peticionario. Los detenidos en verdad tienen derecho a que, si desempeñan labores en los días sábados, domingos y feriados, se les certifique el tiempo laborado, se repite, sin exceder de ocho horas 


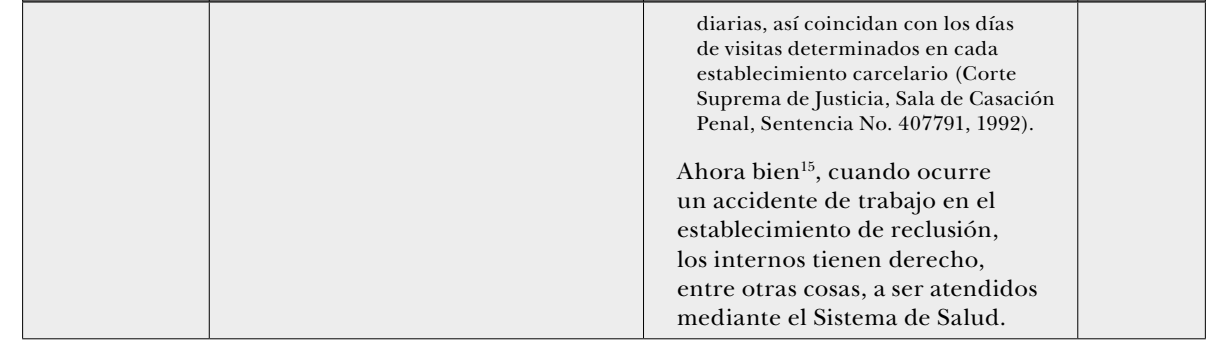

Fuente: elaboración propia.

De acuerdo con lo explorado y descrito en los pronunciamientos de la Corte Constitucional Colombiana desde 1992 hasta el 2020 se puede observar que la Corte ha efectuado un desarrollo progresivo frente al derecho al trabajo de las personas recluidas en centros penitenciarios y carcelarios. Así mismo la corte ha realizado un trabajo de ejecución permanente al aplicar el bloque de constitucionalidad en cada uno de sus fallos, lo que denota el compromiso de Colombia frente a la garantía, protección y promoción de los derechos humanos. Sin embargo, el Tribunal no ha sido constante en sus pronunciamientos frente al derecho, pues, existen lapsos amplios en los cuales no ha emitido ningún tipo de pronunciamiento, según el método escogido, lo cual acarrea un cierto y posible estancamiento del derecho tratado en esta investigación. La razón es que no existe desarrollo por vía legislativa ni a través de la vía jurisprudencial (figura 1).

15 En relación con este asunto, resulta importante aclarar que, tal y como lo dispone el artículo 27 de la Resolución 3.190 del 2013, si bien el periodo de la incapacidad se remunera económicamente, no se tiene en cuenta para efectos de contabilizar la redención de la pena por trabajo. 
Figura 1. Pronunciamientos de la Corte Constitucional colombiana respecto al trabajo penitenciario

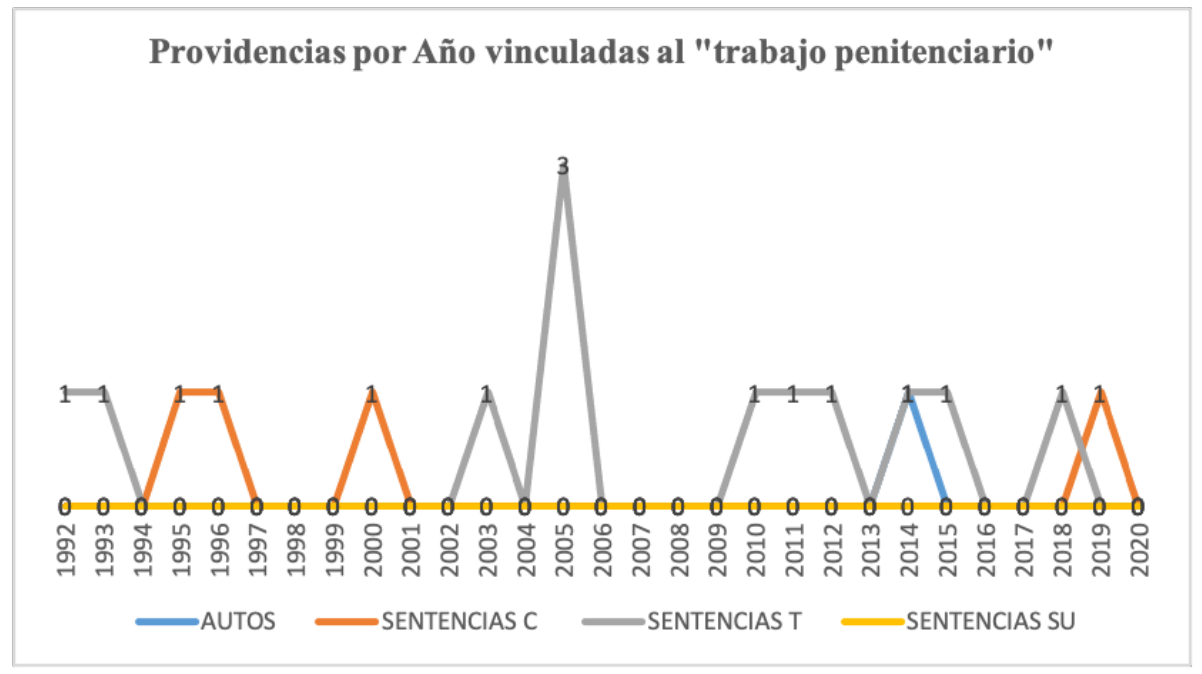

Fuente: elaboración propia

En materia de tipo de pronunciamiento, se tuvieron los siguientes porcentajes (figura 2).

Figura 2. Discriminación de los Pronunciamientos de la Corte Constitucional colombiana respecto al trabajo penitenciario

Tipo de sentencias vinculadas al "trabajo penitenciario"

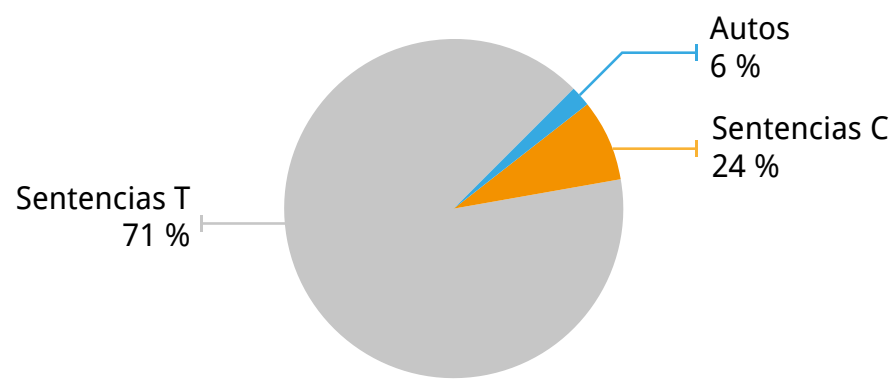

Fuente: elaboración propia. 
Tabla 5. Resultado final de los fallos aplicados en la investigación

\begin{tabular}{|c|c|c|c|c|}
\hline \multirow{2}{*}{$\begin{array}{c}\text { Tipo de } \\
\text { pronunciamiento }\end{array}$} & \multirow{2}{*}{ Autos } & C & SU & T \\
\cline { 3 - 5 } & & 4 & 0 & 12 \\
\hline Total & 1 & &
\end{tabular}

Fuente: elaboración propia.

En conjunto con lo anterior, se decidió representar a su vez, de manera gráfica, los resultados obtenidos partir de la clasificación y valoración cuantitativa de los fallos emitidos por el Tribunal en lo que versa al trabajo penitenciario y carcelario (figura 3).

Figura 3. Asignación de valores a los fallos analizados en la investigación

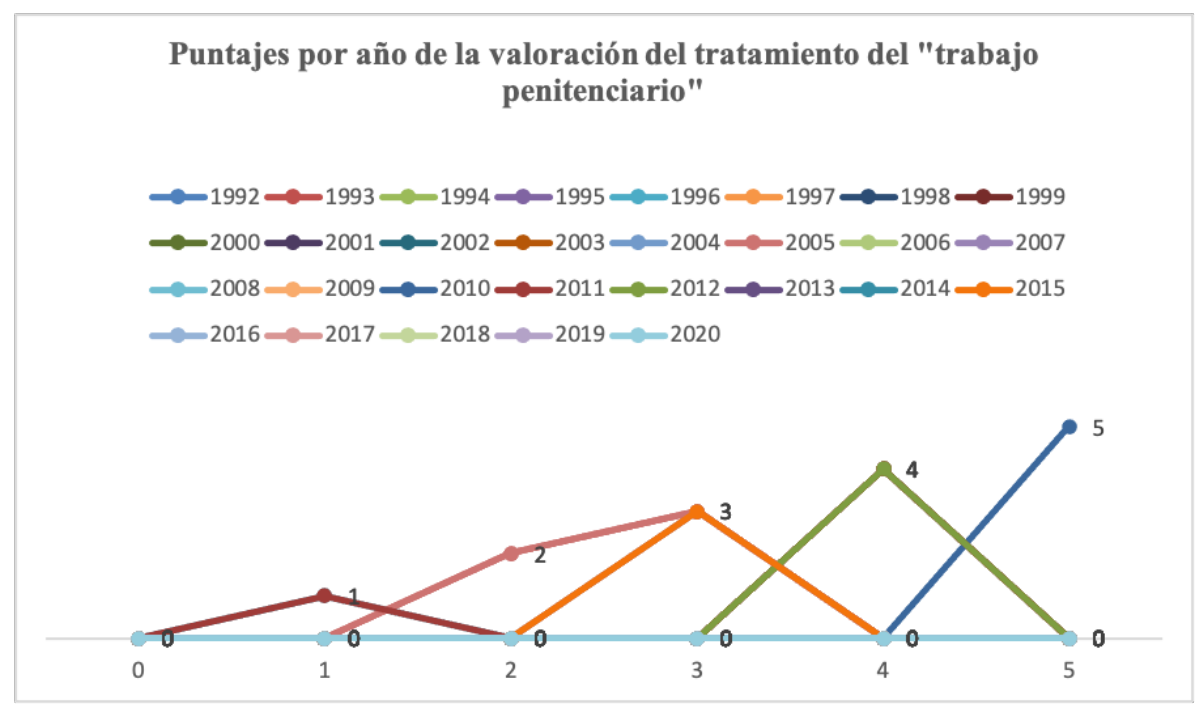

Fuente: elaboración propia.

Estas figuras muestran el cumplimiento de los planteamientos realizados en el presente trabajo de investigación. Se concluye, por una parte, la falta de continuidad en los fallos de la Corte frente al derecho al trabajo de las personas privadas de su libertad. Por otro lado, se enaltece la labor realizada, ya que, si bien los avances no han sido constantes, los aportes han sido sustanciales y significativos para la materializar la efectividad del derecho. 


\section{CONCLUSIONES}

En el marco de un Estado Constitucional (Fuentes-Contreras, 2019A) que debe garantizar los derechos humanos, la Corte Constitucional colombiana, entre 1992 y el 2020, ha creado, reconocido y desarrollado, en materia del trabajo penitenciario y carcelario, el derecho de los reclusos a:

- Laborar en instalaciones y con herramientas que cumplan con los parámetros mínimos de la seguridad industrial.

- La igualdad en materia de derechos laborales.

- La libertad de escoger su profesión u oficio a desarrollar en el tiempo de su reclusión.

- Tener una remuneración equitativa.

- Tener un día de descanso remunerado.

- Al pago de las incapacidades e indemnizaciones por consecuencia de un accidente de trabajo o enfermedad laboral.

- Tener las prestaciones sociales correspondientes a un contrato de trabajo cuando la prestación del servicio sea ante un ente diferente al centro penitenciario y carcelario.

El Estado tiene la obligación de generar estrategias para la participación y vinculación efectiva de los demás actores sociales en el proceso de resocialización. Para esto es clave la gestión de apoyo nacional e internacional, así como la expedición de disposiciones internas de exenciones tributarias y convenios de cooperación entre otras acciones.

El trabajo penitenciario no debe ser visto solo como una forma de redimir la pena, sino que ha de tenerse en cuenta también que, si se le permite percibir un ingreso económico al reo a través de la ejecución de diferentes labores, este podrá atender, además de sus propias necesidades en la prisión, las de su familia y sufragar los gastos de su nueva vida al ser puesto en libertad. Lo anterior guarda directa relación con obligaciones pecuniarias que debe cumplir el condenado, entre las que se encuentran la reparación a la víctima.

\section{REFERENCIAS}

Congreso de Colombia. (1993, 20 de agosto). Por medio de la cual se expide el Código Penitenciario y Carcelario. [ Ley 65 de 1993]. DO: 40.999. Congreso de Colombia. (2004, 31 de agosto). Código de procedimiento penal. [Ley 906 de 2004]. DO: 45.658. 
Congreso de Colombia. (2012, 11 de julio). Por la cual se modifica el Sistema de Riesgos Laborales y se dictan otras disposiciones en materia de Salud Ocupacional. [Ley 1.562 de 2012]. DO: 48.488.

Congreso de Colombia. (2014, 20 de enero). Por medio de la cual se reforman algunos artículos de la Ley 65 de 1993, la ley 599 de 2000, la Ley 55 de 195 y se dictan otras disposiciones. [Ley 1.709 de 2014]. DO: 49.039.

Constitución política de Colombia [Const.]. (1991). Legis.

Convenio sobre el trabajo forzoso. (1957, 25 de junio). https://www.ohchr.org/SP/ ProfessionalInterest/Pages/AbolitionOfForcedLabourConvention.aspx.

Convenio sobre la abolición del trabajo forzoso. (1957, 25 de junio). https://www. ilo.org/dyn/normlex/es/f?p=NORMLEXPUB:12100:0::NO::P12100_ILO_CO DE:C105.

Corte Constitucional. (1992, 11 de diciembre). Sentencia T 601. [MP Eduardo Cifuentes Muñoz.]

Corte Constitucional. (1993, 18 enero). Sentencia T 009 [MP Eduardo Cifuentes Muñoz].

Corte Constitucional. (1993, 29 de marzo). Sentencia T 121. [MP Vladimiro Naranjo. Mesa].

Corte Constitucional. (1995, 7 de septiembre). Sentencia C 394. [MP Vladimiro Naranjo Mesa].

Corte Constitucional. (1996, 13 de junio). Sentencia C 261. [MP Alejandro Martínez Caballero].

Corte Constitucional. (1996, 27 de mayo). Sentencia C 430. [MP Jorge Ignacio Pretelt Chaljub].

Corte Constitucional. (1998, 28 de abril). Sentencia T 153. [MP Eduardo Cifuentes Muñoz].

Corte Constitucional. (2000, 31 de julio). Sentencia T 966. [MP Eduardo Cifuentes Muñoz].

Corte Constitucional. (2000, 8 de noviembre). Sentencia C 1.510. [MP José Gregorio Hernández Galindo].

Corte Constitucional. (2003, 4 de diciembre). Sentencia T 1.190. [MP Eduardo Montealegre Lynett].

Corte Constitucional. (2005, 21 de octubre). Sentencia T 1.077. [MP Jaime Córdoba Triviño].

Corte Constitucional. (2005, 9 de diciembre). Sentencia T 1.303. [MP Jaime Córdoba Triviño].

Corte Constitucional. (2010, 23 de noviembre). Sentencia C 936. [MP Luis Ernesto Vargas Silva].

Corte Constitucional. (2010, 28 de mayo). Sentencia T 429. [MP Juan Carlos Henao Pérez].

Corte Constitucional. (2011, 14 de abril). Sentencia T 286. [MP Jorge Ignacio Pretelt Chaljub].

Corte Constitucional. (2012, 25 de octubre). Sentencia T 865. [MP Alexei Julio Estrada]. 
Corte Constitucional. (2014, 24 de junio). Sentencia C 384. [MP Jorge Ignacio Pretelt Chaljub].

Corte Constitucional. (2015, 10 de diciembre). Sentencia T 756. [MP Luis Guillermo Guerrero Pérez].

Corte Suprema de Justicia, Sala de Casación Penal. (1992, 30 de julio). Radicado n. ${ }^{\circ}$ 407.791. [MP Gustavo Gómez Velásquez].

Corte Suprema de Justicia, Sala de Casación Penal. (2004, 15 de septiembre). Radicado n. ${ }^{\circ}$ 22.777. [MP Sigifredo Espinosa Pérez].

Coyle, A. (2009). La administración penitenciaria en el contexto de los derechos humanos. Centro Internacional de Estudios Penitenciarios.

Fuentes-Contreras, E.H. (2010). Materialidad de la Constitución. La doctrina del bloque de constitucionalidad en la jurisprudencia de la Corte Constitucional. Ibáñez.

Fuentes-Contreras, E.H. (2017). Sistema de fuentes colombiano e implementación del Acuerdo de Paz. Derechos en Acción, 2 (5), 91-126. https://doi. org $/ 10.24215 / 25251678 \mathrm{e} 089$.

Fuentes-Contreras, E.H. (2019). El reconocimiento de la personalidad jurídica en el Sistema Interamericano de derechos humanos. Revista de la Facultad de Derecho de México, 69 (274-2), 753-777. http://dx.doi.org/10.22201/fder.24488 933e.2019.274-2.70044.

Fuentes-Contreras, E.H. (2019A). Del Estado constitucional al Estado convencional de Derecho. Estudio Preliminar sobre el modelo del Estado Convencional de Derecho, en el contexto latinoamericano. Revista Jurídica Digital UANDES, 3 (2), 13-42. http://dx.doi.org/10.24822/rjduandes.0302.2.

Fuentes-Contreras, E.H. (2020). Encontrando el precedente: investigación formativa, metodologías y resultados en el estudio de las percepciones jurisprudenciales internacionales”. En E. Prieto-Rios, P. A. Acosta Alvarado, \& D. Rivas-Ramírez (Eds.), Repensar la educación en derecho internacional en A mérica Latina: avances y discusiones en 2019 (pp 173-200). Universidad del Rosario.

Fuentes-Contreras, E.H. y Cárdenas-Contreras, L.E. (2021). Deferencia a la soberanía nacional. Práctica y doctrina del margen de apreciación nacional en el Sistema Interamericano de Derecho Humanos. Anuario Mexicano de Derecho Internacional, 21, 197-231.http://dx.doi.org/10.22201/ iij.24487872e.2021.21.15592.

Fuentes-Contreras, E.H. y Rivas-Ramírez, D. (Eds.). (2020). Método(s) y Derecho(s). Tirant lo Blanch y otro.

Fuentes-Contreras, E.H., Suárez López, B. y Rincón Villegas, A. (2014). Facticidad y acción de tutela: presentación preliminar de un estudio empírico de la formulación y efectos de la acción de tutela en el marco colombiano, entre los años 1992-2011. Civilizar, 14 (27), 41-64. https://doi. org/10.22518/16578953.178. 
Instituto Nacional Penitenciario y Carcelario. (2013, 23 de octubre). Por la cual se determinan y reglamentan los programas de trabajo, estudio y enseñanza válidos para evaluación y certificación de tiempo para la redención de penas en el Sistema Penitenciario y Carcelario administrado por el Instituto Nacional Penitenciario y Carcelario, modifica la resolución 2.392 del 2006 y deroga las resoluciones 13.824 del 2007 y 649 del 2009. (Resolución 3.190).

López, D. (2006). El derecho de los jueces (segunda edición). Universidad de los Andes y Legis.

López, D. (2016). Cómo se construyen los derechos. Narrativas jurisprudenciales sobre la o rientación sexual. Universidad de los Andes y Legis.

López, D. (2016A). Eslabones del derecho. El deber de coherencia con el precedente judicial. Universidad de los Andes y Legis.

Moner, R., \& Artiles, A. (2008). El Libro blanco del trabajo en las prisiones europeas, o rganización y gestión de los talleres penitenciarios. Centre d'Iniciatives per a la Reinserció.

Pacto Internacional de Derechos Civiles Políticos. (1966, 16 de noviembre). https://www.coe.int/es/web/compass/the-international-covenant-on-civiland-political-rights

Presidencia de Colombia. (2015, . $^{\circ}$ de septiembre). Por el cual se adiciona al Título 1 de la Parte 2 del Libro 2 del Decreto 1.069 del 2015, Decreto Único Reglamentario del Sector Justicia y del Derecho, un Capítulo 10 que regula las especiales condiciones de trabajo de las personas privadas de la libertad. [Decreto 1.758 del 2015].

Pulido, F. (2008). Elementos relevantes para el análisis de las sentencias de la Corte Constitucional colombiana. Novum Jus, 2(1), 125-152.

Pulido, F. (2018). Jueces y reglas: la autoridad del precedente judicial. Universidad de La Sabana.

Rivas-Ramírez, D. y Fuentes-Contreras, E.H. (2021). Los migrantes irregulares en Colombia ante la crisis del Covid-19 ¿Los últimos en lista?”. En A. de Carvalho Ramos, T. Oliveira Moreira, \& T. Scheila Friedrich (Eds.), Direitos humanos dos migrantes e pandemia (pp. 178-197). Instituto Memória Editora.

Suárez, B. \& Fuentes-Contreras, E.H. (2015). Derecho al reconocimiento de la personalidad jurídica. Concepto y desarrollo en la jurisprudencia de la Corte Interamericana de Derechos Humanos. Revista Prolegómenos Derechos y Valores, $18(36), 65-8$. 